\title{
Identification of Protein Z as a Potential Novel Biomarker for the Diagnosis of Prediabetes
}

\author{
Seung-Hoi Koo \\ Division of Life Sciences, Korea University, Seoul, Korea
}

Type 2 diabetes mellitus (T2DM) has rapidly emerged as one of the major metabolic diseases in modern society [1]. Accounting for more than $90 \%$ of human cases of diabetes, T2DM has become a global health threat in both developing and developed countries worldwide. T2DM is considered to be a chronic metabolic disorder, and it is associated with hyperglycemia due to impaired insulin secretion (via pancreatic $\beta$-cell dysfunction), as well as insulin resistance in the peripheral tissues such as the liver, skeletal muscles, and fat cells [2]. Patients with T2DM have higher risks for developing severe complications such as microvascular complications (retinopathy, nephropathy, and neuropathy) and macrovascular complications (myocardial infarction, stroke) [3]. Due to the severity of the complications associated with T2DM, it is important to identify the optimal diagnostic tools for prediabetes (a state prior to the development of T2DM) before the progression of the disease.

Glycated hemoglobin (HbAlc) is currently the most universally utilized biomarker for the diagnosis of both prediabetes and T2DM [4]. Elevated HbA1c levels reflect a chronic hyperglycemic state, and are more highly associated with microvascular complications than fasting plasma glucose (FPG). Although it is a convenient biomarker for detecting prediabetes and T2DM, the usage of HbAlc has limitations due to its moderate sensitivity compared with more traditional methods, such as FPG and the oral glucose tolerance test $[5,6]$. Moreover, cer-

Received: 26 May 2021, Accepted: 3 June 2021

Corresponding author: Seung-Hoi Koo

Division of Life Sciences, Korea University, 145 Anam-ro, Seongbuk-gu, Seoul 02841 , Korea

Tel: +82-2-3290-3403, Fax: +82-2-3290-4144, E-mail: koohoi@korea.ac.kr tain conditions that affect the lifespan of red blood cells themselves could impact plasma HbAlc concentrations [7]. Efforts are underway to identify more reliable and convenient biomarkers for the diagnosis of prediabetes and T2DM. Examples include metabolites (ceramide, acyl-carnitine, and high-density lipoprotein), certain classes of mi-RNAs (miR-192 and 193b), and inflammatory cytokines (C-reactive protein, interleukin 6 [IL-6], IL-18, and plasminogen activator inhibitor-1), each of which has unique advantages and limitations [8].

In the current issue of Endocrinology and Metabolism, Bae et al. [9] published a new article regarding the potential role of protein $\mathrm{Z}$ (PROZ) as a novel biomarker for prediabetes and T2DM. In this study, the authors used blood samples from groups with normoglycemia, prediabetes, and T2DM to detect specific cytokines that were significantly correlated with the disease state by using a cytokine microarray analysis. Thirtythree cytokines were differentially identified in the blood samples from the prediabetic and T2DM groups compared with the normoglycemic group, showing a strong enrichment of biological processes such as immune and inflammatory responses. Interestingly, the level of PROZ was significantly lower in individuals with prediabetes or T2DM than in the normoglycemic control group, and this finding was validated with an enzymelinked immunosorbent assay analysis. PROZ, a plasma glycoprotein secreted from the liver [10], has been shown to inhibit
Copyright $\odot 2021$ Korean Endocrine Society

This is an Open Access article distributed under the terms of the Creative Commons Attribution Non-Commercial License (https://creativecommons.org/ licenses/by-nc/4.0/) which permits unrestricted non-commercial use, distribution, and reproduction in any medium, provided the original work is properly cited. 
blood coagulation and to display a negative correlation with the incidence of vascular disorders [11-13], without any association with glycemia. Indeed, PROZ showed a negative correlation with FPG and HbAlc, which are markers for glycemic disorders, suggesting that it could serve as a potential novel biomarker for prediabetes and T2DM. Based on the proposed role of $\mathrm{PROZ}$, it is plausible to predict that reduced plasma PROZ might be involved in the vascular complications that are associated with T2DM.

In conclusion, the study by Bae et al. [9] identified PROZ as a potential novel biomarker for diagnosing prediabetes and T2DM, which requires further validation. An analysis of a larger cohort in a longitudinal study should be conducted to monitor plasma PROZ levels. Given its potential association with vascular disorders [12,13], it is desirable to delineate the potential role of PROZ in glycemia and/or the development of vascular disorders in T2DM. Regardless, the current study provides a novel insight regarding a newly-discovered potential biomarker for prediabetes that may be helpful to reduce the risk of progression to $\mathrm{T} 2 \mathrm{DM}$ in the future.

\section{CONFLICTS OF INTEREST}

No potential conflict of interest relevant to this article was reported.

\section{ORCID}

Seung-Hoi Koo https://orcid.org/0000-0001-8769-2879

\section{REFERENCES}

1. Ogurtsova K, da Rocha Fernandes JD, Huang Y, Linnenkamp U, Guariguata L, Cho NH, et al. IDF Diabetes Atlas: global estimates for the prevalence of diabetes for 2015 and 2040. Diabetes Res Clin Pract 2017;128:40-50.

2. DeFronzo RA, Ferrannini E, Groop L, Henry RR, Herman
WH, Holst JJ, et al. Type 2 diabetes mellitus. Nat Rev Dis Primers 2015;1:15019.

3. Milman S, Crandall JP. Mechanisms of vascular complications in prediabetes. Med Clin North Am 2011;95:309-25.

4. American Diabetes Association. Diagnosis and classification of diabetes mellitus. Diabetes Care 2014;37 Suppl 1: S81-90.

5. Bonora E, Tuomilehto J. The pros and cons of diagnosing diabetes with A1C. Diabetes Care 2011;34 Suppl 2:S18490.

6. Olson DE, Rhee MK, Herrick K, Ziemer DC, Twombly JG, Phillips LS. Screening for diabetes and pre-diabetes with proposed A1C-based diagnostic criteria. Diabetes Care 2010;33:2184-9.

7. Radin MS. Pitfalls in hemoglobin A1c measurement: when results may be misleading. J Gen Intern Med 2014;29:38894.

8. Dorcely B, Katz K, Jagannathan R, Chiang SS, Oluwadare B, Goldberg IJ, et al. Novel biomarkers for prediabetes, diabetes, and associated complications. Diabetes Metab Syndr Obes 2017;10:345-61.

9. Bae YU, You JH, Cho NH, Kim LE, Shim HM, Park JH, et al. Association of protein $\mathrm{Z}$ with prediabetes and type 2 diabetes. Endocrinol Metab 2021;36:637-46.

10. Broze GJ Jr, Miletich JP. Human protein Z. J Clin Invest 1984;73:933-8.

11. Broze GJ Jr. Protein Z-dependent regulation of coagulation. Thromb Haemost 2001;86:8-13.

12. Fedi S, Sofi F, Brogi D, Tellini I, Cesari F, Sestini I, et al. Low protein $\mathrm{Z}$ plasma levels are independently associated with acute coronary syndromes. Thromb Haemost 2003;90: 1173-8.

13. Heeb MJ, Paganini-Hill A, Griffin JH, Fisher M. Low protein $\mathrm{Z}$ levels and risk of ischemic stroke: differences by diabetic status and gender. Blood Cells Mol Dis 2002;29:13944. 